\title{
Dermatoscopy: an auxiliary resource for the diagnosis of poroid neoplasms*
}

\author{
Maria Isabel Ramos Saraiva ${ }^{1}$, Paula Silva Ferreira' ${ }^{2}$, João Avancini ${ }^{2}$, Neusa Yuriko Sakai Valente ${ }^{2,3}$
}

DOI: http:/ / dx.doi.org/10.1590/abd1806-4841.20187570

\begin{abstract}
Poroid neoplasms are benign epithelial proliferations with eccrine sweat gland differentiation. They are a challenging diagnosis because of the clinical heterogeneity, being able to mimic several malignant neoplasms. They are classified into classic poroma, hidroacanthoma simplex, dermal duct tumor and poroid hidradenoma. Association of histological subtypes occurs in more than $25 \%$ of cases. We report a case of a combined poroid neoplasia of classical poroma and poroid hidradenoma, reviewing its dermatoscopic features.
\end{abstract}

Keywords: Dermoscopy; Neoplasms; Neoplasms, ductal, lobular, and medullary; Poroma; Sweat gland neoplasms

Poroid neoplasms are benign epithelial proliferations, with sweat gland differentiation, that are classified according to its histological characteristics into: classic poroma, hidroacanthoma simplex, dermal duct tumor and poroid hidradenoma. ${ }^{1,2}$ They have in common aggregates of basophilic poroid cells, eosinophilic cuticular squamous cells and small ductal. Classic poroma exhibits dermal lobular proliferation connected to the epidermis. In turn, hidroacanthoma simplex is an intraepidermal proliferation. In the dermal duct tumor, the aggregates of poroid cells are small, with little or no connection to the epidermis. Poroid hidradenoma consists in an aggregate of poroid and cuticular cells, single or few and large, with cystic areas in the dermis or subcutaneous tissue. ${ }^{1}$ The association between the histological subtypes is present in up to $27.3 \%$ of cases. ${ }^{1,2}$

They are a challenging diagnosis due to the clinical heterogeneity, mimicking other malignant neoplasms such as melanoma and squamous and basal cells carcinomas. Dermatoscopy can help in differentiating these lesions..$^{1-3}$
There are few dermatoscopic descriptions of poroid neoplasms, with no dermatoscopic description of combined poroid neoplasms. In this article, we report the clinical, histological and dermatoscopic aspects of a combined poroid neoplasm of classic poroma and poroid hidradenoma and review the most common dermatoscopic aspects already described for these neoplasms, in search if features that aid in their differentiation.

A 70 year-old woman, with a history of multiple dysplastic nevi and family history of melanoma, had a progressively enlarging well-defined blue-grey nodule with $1 \mathrm{~cm}$ in diameter on the scalp for 2 years (Figure 1A). Dermatoscopy revealed a white-blue peripheral homogeneous pattern associated to the central area, with brown blotches and "out of focus" linear and glomerular telangiectasias (Figures 1B and 1C). the initial diagnostic hypotheses were pigmented basal cell carcinoma, blue nevus and malignant melanoma. The patient was submitted to an excisional biopsy and histopathology showed a benign epithelial neoplasm, with small basaloid cells,

\footnotetext{
Received 21 August 2017.

Accepted 06 November 2017.

* Work conducted at Hospital das Clínicas, Faculdade de Medicina, Universidade de São Paulo, São Paulo (SP), Brazil.

Financial support: None.

Conflict of interest: None.

Service of Dermatology, Hospital Alemão Oswaldo Cruz, São Paulo (SP), Brazil.

Service of Dermatology, Hospital das Clínicas, Faculdade de Medicina, Universidade de São Paulo, São Paulo (SP), Brazil.

Service of Dermatology, Hospital do Servidor Público Estadual, São Paulo (SP), Brazil.
}

\section{MAILING AdDRESS:}

Maria Isabel Ramos Saraiva

E-mail: isabelsaraivadermato@gmail.com

(C)2018 by Anais Brasileiros de Dermatologia 

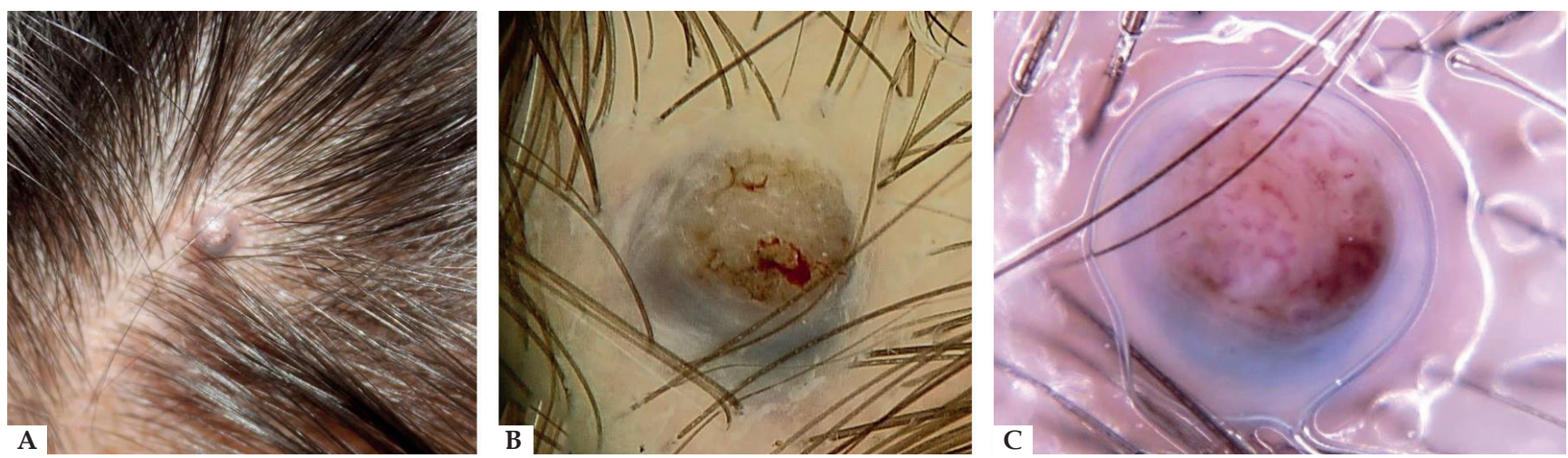

Figure 1: A - Clinical aspect: well-defined blue-grey nodule with $1 \mathrm{~cm}$ diameter. B and C - Dermatoscopic aspect: white-blue homogeneous peripheral pattern associated to a central area with brown blotches and "out of focus" linear and glomerular telangiectasias

sometimes melanized, and squamous cells around small ducts (Figures 2 to 5). The neoplasm exhibited anastomosed cords connected to the epidermis in the upper part, and lobular aspect extending to the subcutaneous tissue in the lower part. These findings allowed the diagnosis of pigmented combined poroid neoplasm (eccrine poroma and poroid hidradenoma).

Classic poroma appears as a firm, skin-colored or erythematous nodule, papule or plaque, mainly on palms and soles. It is more frequent between the fourth and sixth decades of life and has no gender predilection. Its pathogenesis is unknown, related to trauma, radiation or scar. The pigmented variant, which corresponds to $17 \%$ of cases and is apparently more frequent in higher phototypes affecting non-acral sites, is underdiagnosed and mistaken for seborrheic keratosis, pyogenic granuloma, basal cell carcinoma (BCC), squamous cell carcinoma, angiofibroma and cutaneous melanoma. ${ }^{3}$

On dermatoscopy, the pattern polymorphic vessels, found in this case, is the most commonly described. Besides this, vascular patterns with flower- or leaf-like vessels were described as specific, and a pattern of a network of white lines or interlacing white cords as suggestive. ${ }^{4}$ In the pigmented variant, there are reports of arborizing vessels, ovoid nests and blue-grey dots. ${ }^{5}$ Bronfenbrener et al suggested the out-of-focus appearance seen in these vessels could be due to the depth inside the poroid tumor in comparison to BCC. ${ }^{6}$ Irregular pigmented globules can mimic melanoma or BCC. ${ }^{6}$ Minagawa et al described vascular alterations beyond globule-like and comedo-like structures as the most relevant findings. ${ }^{7}$ Brugués describes the dermatoscopy as a structureless erythematous nodule, with a scaly surface, white circles and central ulceration. ${ }^{8}$

Poroid hidradenoma is a subtype of nodular hidradenoma with eccrine differentiation. ${ }^{9}$ Nonspecific, solitary cutaneous or subcutaneous lesions, polypoid nodules or cysts from 1 to $2 \mathrm{~cm}$ in diameter are described, that can be erythematous or blue and can ulcerate, with no anatomical predilection. ${ }^{1}$ Ito et al described scalp, face, neck and genitalia as the most commonly affected sites. ${ }^{2}$ Serrano et al published a series of 28 cases in which the most commonly found dermatoscopic pattern was erythematous homogeneous area in the non-pigmented and blue or brown in the pigmented, occupying the whole lesion, with vascular and white strucutures. ${ }^{10}$ The three most common vascular structures were arborizing telangiectasias,

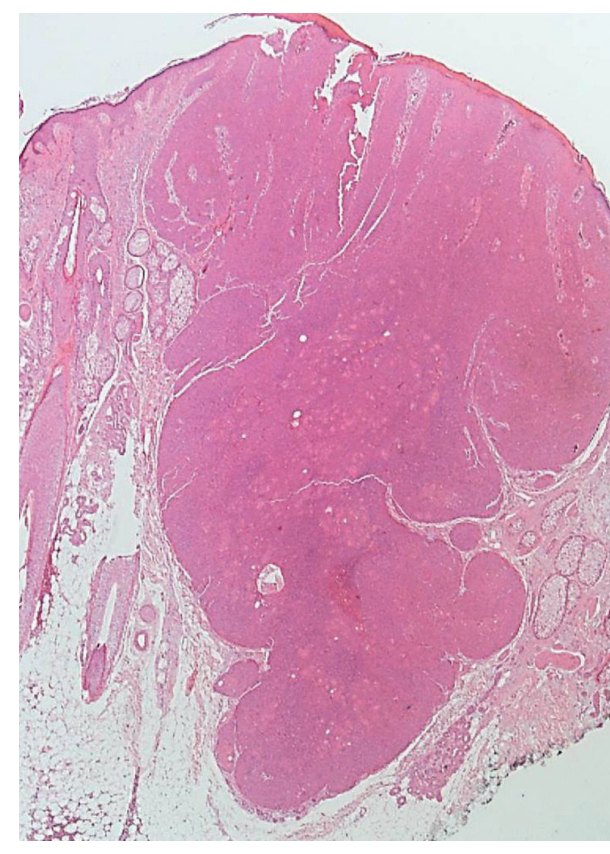

Figure 2: Benign epithelial neoplasm exhibiting an aspect of poroma in the upper part (anastomosed cords of poroid cells connected to the epidermis). In the lower part, aspect of nodular hidradenoma extending to the subcutaneous tissue (Hematoxylin \& eosin, $\mathrm{x} 40)$

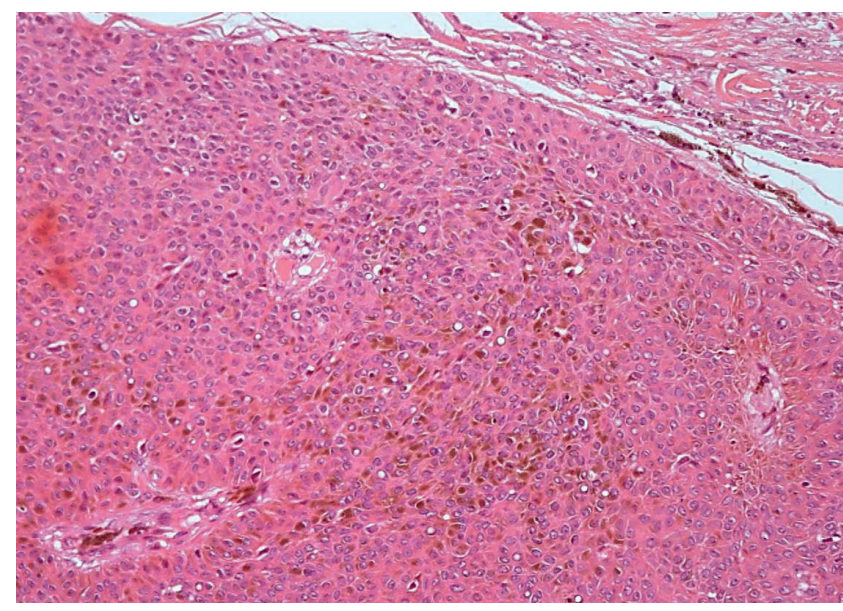

FIGURE 3: Close up of the benign poroid epithelial neoplasm, showing poroid melanized cells (basaloid) with no atypia (Hematoxylin \& eosin, x200) 


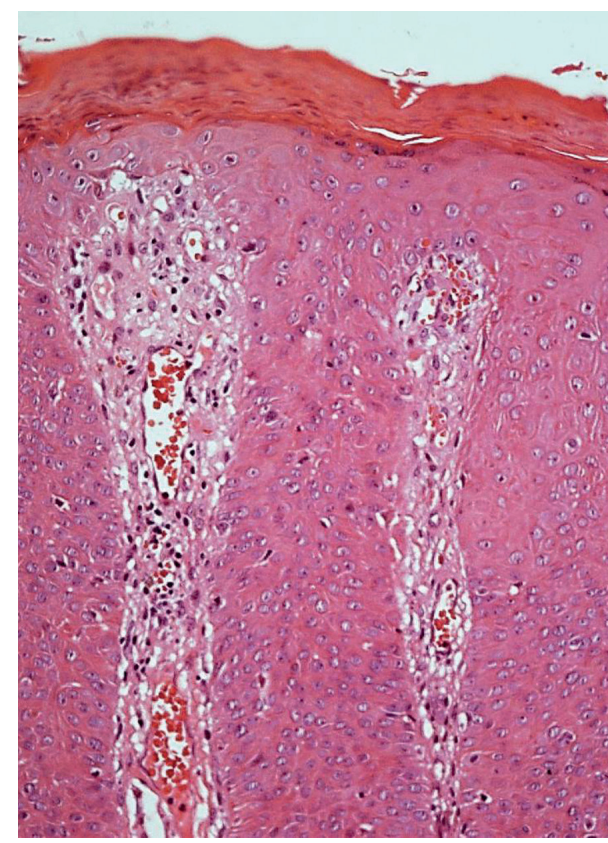

FIGURE 4: Benign poroid epithelial neoplasm: close up of the crust and well vascularized stroma (Hematoxylin \& eosin, $\times 200$ )

atypical polymorphic vessels or linear irregular vessels. Peripheric network was described in $17.9 \%$. These patterns are not specific. ${ }^{10}$

The literature review we conducted did not enable us to distinguish which dermatoscopic findings correspond to classic poroma or to poroid hidradenoma, since most of them overlap, confirming the spectral view of these neoplasms.

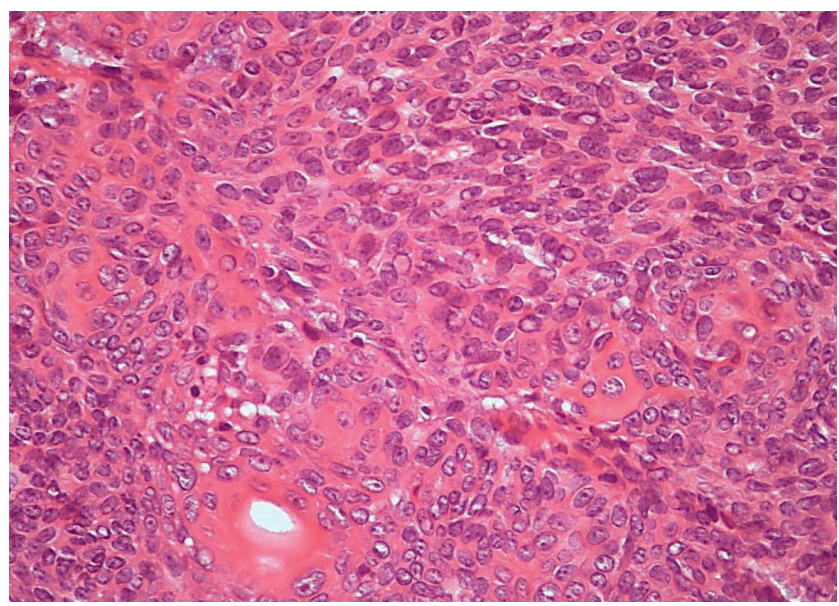

FIGURE 5: Benign poroid epithelial neoplasm: close up of poroid cells (basaloid) and cuticular cells (squamous) around the duct (Hematoxylin \& eosin, $x 400$ )
Although the diagnosis of poroid neoplasms continues to depend on histological findings, the dermatoscopic findings of each of these tumors will help rule out the diagnosis of melanoma and other non-melanoma cancers, noting that, in up to a fourth of the cases, the tumor is combined. Such was what occurred in this case, in which more than one pattern could be found. $\square$

\section{REFERENCES}

1. Battistella M, Langbein L, Peltre B, Cribier B. From hidroacanthoma simplex to poroid hidradenoma: clinicopathologic and immunohistochemic study of poroid neoplasms and reappraisal of their histogenesis. Am J Dermatopathol. 2010;32:459-68

2. Ito K, Ansai SI, Fukumoto T, Anan T, Kimura T. Clinicopathological analysis of 384 cases of poroid neoplasms including 98 cases of apocrine type cases. J Dermatol. 2017;44:327-334.

3. Bombonato C, Piana S, Moscarella E, Lallas A, Argenziano G, Longo C. Pigmented eccrine poroma: dermoscopic and confocal features. Dermatol Pract Concept. 2016;6:59-62.

4. Shalom A, Schein O, Landi C, Marghoob A, Carlos B, Scope A. Dermoscopic findings in biopsy-proven poromas. Dermatol Surg. 2012;38:1091-6.
5. Kuo HW, Ohara K. Pigmented eccrine poroma: a report of two cases and study with dermatoscopy. Dermatol Surg. 2003;29:1076-9

6. Bronfenbrener R, Cohen J, Slutsky JB. Conflicting dermoscopic criteria in a suspicious lesion. JAMA Dermatol. 2015;151:553-4.

7. Minagawa A, Koga H. Dermoscopy of pigmented poromas. Dermatology. 2010 ;221:78-83.

8. Brugués A, Gamboa M, Alós L, Carrera C, Malvehy J, Puig S. The challenging diagnosis of eccrine poromas. J Am Acad Dermatol. 2016;74:e113-5.

9. Monteagudo B, Iglesias B, de la Torre C, Paredes C, Vázquez-Blanco M, Ginarte M, et al. Hidroadenoma poroide. Actas. Dermosifiliogr. 2005:96:398-9.

10. Serrano P, Lallas A, Del Pozo LJ, Karaarslan I, Medina C, Thomas L, et al. Dermoscopy of Nodular Hidradenoma, a Great Masquerader: A Morphological Study of 28 Cases. Dermatology. 2016;232:78-82.

\section{AUTHORS'CONTRIBUTION}

Maria Isabel Ramos Saraiva

iD ORCID 0000-0002-5043-489X

Approval of the final version of the manuscript, Conception and planning of the study, Elaboration and writing of the manuscript, Obtaining, analyzing and interpreting the data, Critical review of the literature, Critical review of the manuscript
Paula Silva Ferreira
(iD) ORCID 0000-0003-3868-5191

Approval of the final version of the manuscript, Conception and planning of the study, Elaboration and writing of the manuscript, Obtaining, analyzing and interpreting the data, Effective participation in research orientation, Intellectual participation in propaedeutic and/or therapeutic conduct of the cases studied, Critical review of the manuscript João Avancini $\quad$ (iD) ORCID 0000-0003-3038-6373

Effective participation in research orientation, Intellectual participation in propaedeutic and/or therapeutic conduct of the cases studied

Neusa Yuriko Sakai Valente $\quad$ (iD) ORCID 0000-0002-8065-2695

Approval of the final version of the manuscript, Effective participation in research orientation, Intellectual participation in propaedeutic and/or therapeutic conduct of the cases studied, Critical review of the manuscript

How to cite this article: Saraiva MIR, Ferreira PS, Avancini J, Valente NYS. Dermatoscopy: an auxiliary resource for the diagnosis of poroid neoplasms. An Bras Dermatol. 2018;93(6):896-8. 